\title{
Demokrasi ve Mutluluk: BRIC ve MIST Ülkeleri Üzerine Bir Araștırma
}

\author{
Rabia EFEOĞLU \\ Sorumlu Yazar, Kastamonu Üniversitesi, İ̈BF, Finans ve Bankacılık Bölümü, \\ refeoglu@kastamonu.edu.tr, ORCID:0000-0003-2515-1553
}

Sabri AZGÜN

Atatürk Üniversitesi, IIIBF, İktisat Bölümü, sabriazgun@atauni.edu.tr, ORCID:0000-0002-3349-2158

\begin{abstract}
Öz
Günümüzde yeni bir kalkınma göstergesi olan ve nitel bir kavram olan mutluluk ekonomik kalkınmayla ilişkilendirilen önemli bir konudur. Son yıllarda demokrasinin, bir kalkınma göstergesi olan mutluluğu nasıl etkilediği literatürde dikkat çekmektedir. Mutluluğun birçok değişkenle ilişkisinin araştırıldığı çok sayıda çalışma olmasına rağmen; mutluluk, demokrasi, büyüme ilişkisine literatürde az sayıda rastlanılmıştır. Bu kapsamda çalışmanın amacı, demokrasinin mutluluk düzeyine etkisini mevcut yükselen ekonomiler olarak bilinen BRIC (Brezilya, Rusya, Hindistan, Çin) ve yeni yükselen ekonomiler olarak bilinen MIST (Meksika, Endonezya, Güney Kore, Türkiye) ülkelerini oluşturan 8 ülke için 2013-2018 dönemine ait veriler ile panel sıralı nitel tercih yöntemini kullanarak araştırmaktır. Araştırmada demokrasinin mutluluğun yüksek düzeylerinde daha etkili ve yüksek mutluluk düzeyini etkileme olasılığının daha yüksek olduğu sonucu elde edilmiştir.
\end{abstract}

Anahtar Kelimeler: Mutluluk Endeksi, Demokrasi, Kişi Başına GSYH

Jel Sınıflandırma Kodları: I30, F59, O40

\section{Democracy and Happiness: A Research on BRIC and MIST Countries ${ }^{1}$}

\begin{abstract}
Today, happiness, which is a new development indicator and qualitative concept, is an important issue associated with economic development. In recent years, the literature draws attention to how democracy affects happiness, which is a development indicator. Although there are many studies investigating the relationship between happiness and many variables; the relationship between happiness, democracy and growth is rarely encountered in the literature. In this context, the aim of this study is to investigate the effect of democracy on the level of happiness BRIC (Brazil, Russia, India, China) which are known as current emerging economies and MIST (Mexico, Indonesia, South Korea, Turkey) which are known as new emerging economies, data from 2013-2018 period for all 8 countries, using panel-based qualitative choice method. In the study, it was concluded that democracy is more effective at higher levels of happiness and is higher likely to affect the higher level of happiness.
\end{abstract}

Keywords: Happiness Index, Democracy, Per Capita GDP

Jel Classification Codes: I30, F59, O40

\footnotetext{
${ }^{1}$ Extended abstract is presented at the end of the article.

Geliş Tarihi (Received): 18.09.2020 - Kabul Edilme Tarihi (Accepted): 22.06.2021

Atıfta bulunmak için / Cite this paper:

Efeoğlu, R. ve Azgün, S. (2021). Demokrasi ve Mutluluk: BRIC ve MIST Ülkeleri Üzerine Bir Araştırma. Çankırl Karatekin Üniversitesi İ̈BF Dergisi, 11 (1), 333-349. Doi: 10.18074/ckuiibfd.797139.
} 


\section{Giriş}

Bireylerin daha iyi bir yaşam sürdürebilmeleri için maddi koşullarının iyileştirilmesinin yanı sıra bireysel yetenek ve özgürlüklerinin de genişletilmesi gerekmektedir. Böylelikle refahın artırılmasında kişi başına düşen gelir artışının yanında mutluluk gibi bir kavramın öne çıkması söz konusu olmuştur. Bu durum ise, kalkınmanın farklı bir bakış açısıyla ele alınmasını gündeme getirmiştir. Mutluluk; barınma, sağlık, eğitim, kişi başına düşen gelir, refah düzeyi, gelirin dağılımı, özgürlükler, iyi yönetim, çalışma durumu, boş zaman, aile ve sosyal ilişkiler, çevresel değerler bakımından kalkınmayı kapsayacak biçimde geniş bir açıdan değerlendirilebilir. Son zamanlarda kalkınma, insanı merkez alan bir anlayış içerisinde olduğundan mutluluk ile önemli bir ilișkisi vardır. Mutluluk kalkınmanın en önemli göstergeleri arasındadır ve kalkınma yarışında mutlu toplumların öne çıkma potansiyeli daha yüksektir (Aktaş, 2015, s. 51). İnsanlar kişi başına gelirlerinde meydana gelen artışın beraberinde getirdiği yaşam standartlarının iyileşmesine bağlı olarak daha mutlu olabileceklerdir.

Ekonomik gelişme için mutluluğun artırılması gereklidir, bu noktada mutluluğun tanımı ve ölçülmesi önem arz etmektedir. Tarihsel süreçte kişiden kişiye farklılık gösteren ve farklı tanımlamaları bulunan mutluluğu Veenhoven, "bir kişinin bir bütün olarak kendi hayatının değerini bilmesi" olarak tanımlamaktadır (Veenhoven, 2006, s. 7). Diğer taraftan mutluluğun birçok belirleyicisi olup söz konusu belirleyiciler kişilere göre değişiklik gösterdiğinden mutluluğun ölçülmesi oldukça zordur. Mutluluğun ölçülmesinde literatürde en çok kullanılan ölçümler, Birleşmiş Milletler ve OECD tarafından hazırlanan endekslerdir. Birleşmiş Milletler tarafindan hazırlanan endeksler Dünya Mutluluk Raporunda yer alan Dünya Mutluluk Endeksi, Küresel Mutluluk Endeksi ve Gayri Safi Milli Mutluluk Endeksi; OECD tarafından hazırlanan endeksler Daha İyi Yaşam Endeksi ve Mutlu Gezegen Endeksidir. Mutluluğun ölçülmesinde farklı yöntem ve endeksler kullanılmakla birlikte Dünya Mutluluk Endeksi en yaygın kullanılan mutluluğu ölçme yöntemidir. Mutluluk endeksi, ilk olarak 2012'de John Helliwell, Richard Layard ve Jeffrey Sachs tarafından hazırlanan ve Birleşmiş Milletler Sürdürülebilir Kalkınma Çözümleri Ağı (Sustainable Development Solutions Network (SDSN)) tarafından yayımlanan Dünya Mutluluk Raporunda (World Happiness Report) yer almış ve mutluluk seviyesini ölçmeye yönelik geliştirilmiş bir endekstir. Ülkelerin mutluluk sıralamasını gösteren endeks, Gallup Dünya Anketinden yararlanılarak hesaplanmaktadır. Buna göre insanlardan hayatlarından duydukları memnuniyet düzeyi için, en altta 0 ve en üstte 10 olmak üzere $0-10$ ölçeğinde basamaklardan oluşan bir merdiven düşünmeleri ve kişisel olarak kendilerini bu merdivenin hangi basamağında hissettiklerini belirtmeleri istenmektedir. Böylece sorulara 0 ile 10 puan arasında değerler verilerek mutluluk seviyesi belirlenmektedir. Mutluluk seviyesini belirleyebilmek amaciyla sorularda kişi başına düşen GSYH, doğumda sağlıklı yaşam beklentisi, sosyal destek, hayatta seçim yapma özgürlüğü, cömertlik, yolsuzluk algısı, pozitif etkiler ve 
negatif etkiler kriterleri dikkate alınmaktadır (Helliwell, Layard ve Sachs, 2017, s. 16).

Öte yandan ülkelerin kalkınması özelinde mutluluğu artırmada önemli bir rol oynayan politik etken demokrasidir. Antik Yunan'dan günümüze kadar yıllar içinde değişme gösteren demokrasi en genel anlamıyla, "halkın kendi kendini yönetmesi” olarak tanımlanmaktadır. Demokrasi ölçümü farklı şekillerde ve farklı endekslerle yapılmaktadır. Genel olarak demokrasi literatüründe kabul görmüş demokrasi endeksleri; Freedom House Demokrasi Endeksi, Polity Demokrasi Endeksi, Arat Demokrasi Endeksi, Banks Demokrasi Endeksi, Bollen Demokrasi Endeksi, Poe \& Tate Demokrasi Endeksi, Vanhanen Demokrasi Endeksi, Przeworski Demokrasi Endeksi, Siyasal Kalkınma Endeksi olarak sıralanabilir. Çalışmalarda en yaygın olarak kullanılan ve en güvenilir sonuçlar veren endeks Freedom House Demokrasi Endeksi'dir. Gastil tarafından geliştirilen Freedom House Endeksi, dünyada demokratikleşme sürecini analiz eden ABD'de faaliyet gösteren bir sivil toplum kuruluşu olan Freedom House tarafindan yayınlanmaktadır. Her y1l yayımlanan endeks Freedom in the World adli raporlardan elde edilmektedir. Endeks 1972 yılından beri yayınlanmakta olup siyasal haklar (political rights) ve sivil özgürlükler (civil liberties) olmak üzere iki tür endekse dayanan bir demokrasi ölçüsüdür. Endeks hesaplanırken bir ülkenin demokrasiye sahip olup olmadığını tespit etmek amacıyla vatandaşların adayları hür bir şekilde seçebilmesi, muhalefetin iktidara katılma şanslarının bulunması gibi birkaç temel ölçüt kullanılmıştır. Bu niteliklere sahip siyasal sistemler demokratik sistemler olarak siniflandırılırken, sahip olmayanlar demokratik olmayan sistemler içerisinde yer almaktadır. Freedom House Demokrasi Endeksi, 1 ile 7 değerleri arasındadır, 1 en gelişmiş demokrasileri, 7 demokrasinin olmadığını göstermektedir ve endeks ülkeleri özgür, kısmen özgür, özgür olmayan şeklinde sinıflandırmaktadır.

Demokrasinin mutlulukla ilişkisi, politik rejimin etkisini şekillendirmede bir modeldir. Politik rejimin mutluluğu etkileyebileceği iki yol vardır: ideoloji ve siyasi rejim ile kurum inşası arasındaki ilişki ve siyasi rejime bağımlılık. Bu nedenle, mutluluk seviyesinin siyasi rejimler arasında değişmesi gerektiğini varsaymak mümkündür. Demokrasi düzeyi bakımından üst sıralarda yer alan ülkelerin en mutlu ülkeler olma beklentisi vardır. Mutluluk literatüründe demokrasi ve mutluluk arasındaki ilişki yeterince araştırılmamış, söz konusu ilişki mutluluk ile demografi-ekonomiye odaklanan çalışmalara kıyasla geniş ölçüde ele alınmamıştır. Bu kapsamda çalışma, mevcut yüksselen ekonomiler (BRIC) ile yeni yükselen ekonomilerden (MIST) oluşan 8 ülkede demokrasinin mutluluk düzeyine etkisini analiz etmeyi amaçlar.

Demokrasinin mutluluk düzeyi üzerindeki etkisini belirlemeye yönelik böyle bir çalışmaya daha önce yükselen piyasa ekonomileri ölçeğinde rastlanılmaması çalışmanın önemini ifade etmektedir. Özellikle 2000'li yıllardan itibaren hızlı ve 
etkileyici bir performansa sahip BRIC yükselen piyasa ekonomilerinin yanı sıra 2011 y1lından itibaren MIST yükselen piyasa ekonomilerine odaklanılmas1 sonucu, ülke ekonomilerinin yüksek performans sergilemeye başlaması ve geleceğin önde gelen ekonomileri arasında yer alacağı beklentisinin olması her iki ülke grubunun birlikte çalışmaya konu olarak incelenmesi hususunda önem arz etmektedir. Söz konusu yükselen piyasa ekonomileri dünyada ekonomik, siyasi ve sosyal alanda önemli bir konuma sahip olmaya başlayan ve büyük ilerleme kaydeden ülkelerdir. Ekonomik ve siyasi açıdan giderek güçlenen yükselen ekonomi ülkeleri dünya ekonomisinde yaşanan gelişmelerden yararlanarak ekonomik ve siyasi algıyı tersine çevirip, dünyada meydana gelen hızlı değişimi yüksek gelişme performansı göstererek kendi lehlerine çevirebilmeyi başarabilmişlerdir. Bu anlamda hızlı bir ekonomik büyüme göstermeleri yükselen piyasa ekonomilerinin en temel özelliği olmuş, büyüme yönünden dünya ekonomisinin motoru durumunda olan söz konusu ülkeler ekonomik ve politik anlamda da söz sahibi olmaya hazırlanan ülkeler arasında yer almıştır.

İlgili yükselen ülke ekonomilerinin sahip oldukları olumlu ekonomik görünüm ve yüksek büyüme hızları sayesinde gelecek yıllarda önemli bir kalkınma yaşayacakları beklentisi vardır. Yükselen ekonomilerin tahmin edilen kalkınma performansını gösterirken, sahip oldukları ekonomik reformlarının yanı sıra kurumsal yapılarının da güçlendirilmesi gerekmektedir ki, bu anlamda her iki yükselen ekonomi grubunun demokrasileri bakımından incelenmesi ve kalkınma özelinde mutluluk düzeyi ile ilişkisinin irdelenmesi çalışmanın diğer bir önemini ifade etmektedir. $\mathrm{Bu}$ yönleriyle çalışmanın diğer çalışmalardan ayrılarak mutluluk-demokrasi literatürüne katkı sağlayacağı düşünülmektedir. Çalışma beş bölümden oluşmakta, giriş bölümünden sonra ikinci bölümde literatür taraması, üçüncü bölümde veri seti ve yöntem, dördüncü bölümde analiz, beşinci bolümde sonuçlar sunulmaktadır.

\section{Literatür Taraması}

Literatürde mutluluk üzerine yapılan ve çeşitli faktörlerin (gelir, demografik faktörler vb.) mutluluğa etkisini inceleyen çalışmalar olmakla birlikte her biri farklı yöntemler kullanarak farklı sonuçlar elde etmiştir. Bu çalışmalardan Shahbaz ve Aamir (2008), 1973-2006 döneminde Pakistan'da mutluluğun makro belirleyicilerini araştırmışlardır. Buna göre kişi başına GSYH, enflasyon, dolaylı vergilerdeki artışlar ile kentleşme oranındaki azalış mutluluk düzeyini azaltırken; işçi dövizlerindeki artış ve ticari açıklık mutluluk düzeyini iyileştirmektedir. Perovic ve Golem (2010), makroekonomik değişkenlerin mutluluk üzerine etkisini 13 geçiş ülkesi için incelemişlerdir. GSYH ve devlet harcamalarının mutluluğu olumlu etkilediği sonucunu bulmuşlardır. Abounoori ve Asgarizadeh (2013) tarafından yapılan çalışmada, 58 ülke için 2003-2011 döneminde mutluluğu etkileyen faktörler incelenmiştir. Enflasyon ve işsizliğin mutluluğu olumsuz, kişi başına GSYH ve devlet harcamalarının olumlu etkilediği görülmüştür. Aktaş 
(2015) tarafından yapılan çalışmada uyum teorisi çerçevesinde mutluluk, insani gelişme ve yoksulluk arasındaki ilişki incelenmiş, mutluluğun yoksulluğa uyum sağlayabildiği sonucuna varılmıştır. Servet (2017), Türkiye'de 2004-2014 döneminde mutluluk ile gelir, yaş, cinsiyet, eğitim, sağlık, refah arasındaki ilişkiyi incelemiştir. Erkeklerin mutluluk düzeylerinin arttığı, insanların yaşlandıkça daha mutlu oldukları ve evli insanların mutluluk düzeylerinin azaldığı belirlenmiştir. Güzel (2018) çalışmasında, OECD ülkelerinde refah ve mutluluğun gelir eşitsizliği üzerindeki etkisini incelemiştir. Gelir eşitsizliğinin daha az olduğu ülkelerde refah ve mutluluk düzeyinin daha yüksek olduğu bulgusuna ulaşmıştır. Kabakçı, Günay ve Ata (2018), ülkelerin mutluluk düzeyi ve gelir seviyesi arasındaki ilişkiyi incelemişlerdir. Gelir düzeyi yüksek olan ülkelerin mutluluk ve refah düzeylerinin daha yüksek olduğu bulgusu elde edilmiştir. Servet (2018) dünya ülkelerinde mutluluk ve kişi başına GSYİH, yolsuzluk algısı, sosyal destek, doğumda sağlıklı yaşam beklentisi, seçim yapma özgürlüğü, ulusal hükümete güven, cömertlik, işsizlik oranı ve enflasyon oranı arasındaki ilişkiyi sıralı logit model ile incelemiştir. Elde edilen bulgulara göre, kişi başına GSYİH, sosyal destek, doğumda sağlıklı yaşam beklentisi, seçim özgürlüğü, cömertlik mutluluk düzeyini artırmakta; yolsuzluk algısı, ulusal hükümete güven, işsizlik ve enflasyon oranındaki artış mutluluk düzeyini azaltmaktadır. Aksaraylı ve Kaya (2020) çalışmalarında, ekonomik özgürlük ve mutluluk arasındaki ilişkiyi 35 OECD ülkesi için analiz etmişler, ekonomik özgürlüğün mutluluğu etkilediği sonucuna ulaşmışlardır.

Diğer taraftan demokrasi-mutluluk literatüründe yer alan demokrasinin mutluluğa etkisini inceleyen ampirik çalışmalardan Frey ve Stutzer (1999), Frey ve Stutzer (2000), Frey ve Stutzer (2002), Frey (2011) yaptıkları çalışmada İsviçre için demokrasinin mutluluk üzerindeki etkisini araştırmışlardır. Demokrasinin mutluluk ile pozitif ilişkili olduğu sonucunu elde etmişlerdir. Graham ve Pettinato (2000) tarafından yapılan çalışmada, 2000 yılı için 17 ülkede demokrasi-mutluluk ilişkisi araştırılmış ve aralarında pozitif bir ilişki bulunmuştur. Dorn vd. (2007), 28 ülke için 1998 dönemi verileriyle demokrasinin mutluluk üzerindeki etkisini sıralı probit yöntemiyle araştırmışlar ancak pozitif bir ilişkiye rastlamamışlardır. Inglehart (2008) ve Inglehart ve Ponarin (2013), 1981-2007 ve 1972-2008 dönemi için demokrasi ve mutluluk ilişkisini incelemişlerdir. Her iki çalışmada da demokrasinin mutlulukla pozitif ilişkili olduğu sonucuna varılmıştır. Kroll (2012), AB ülkeleri üzerine yaptığı çalışmasında demokrasi ve mutluluk arasında pozitif bir ilişki bulmuştur. Steffen ve Vatter (2012), İsviçre için demokrasi ve mutluluk ilişkisini incelemişler, fakat pozitif bir ilişki bulamamışlardır. Ekici ve Koydemir (2014), Türkiye için 1999 ve 2008 y1llarında demokrasi-mutluluk ilişkisini sıralı probit model analiziyle inceleyerek pozitif bir ilişki yakalamışlardır. Knutsen (2015), 100 ülke için 2000-2004 verilerini kullanarak sıralı nitel tercih analiz yöntemi ile demokrasinin mutluluk üzerindeki etkisini araştırmış ve pozitif bir sonuç elde etmiştir. Dimitrova (2016) tarafından yapılan çalışmada, demokrasi ve mutluluk ilişkisi Sovyet sonrası devletler için araştırılmış ve aralarında pozitif 
ilişki olduğu sonucuna varılmıştır. Loubser ve Steenekamp (2016) tarafindan yapılan çalışmada, 2010-2014 döneminde 10 ülke için demokrasi ve mutluluk ilişki araştırılmış ancak pozitif bir ilişki bulunamamıştır. Potts (2016) tarafından yapılan çalışmada demokrasinin mutluluğu pozitif etkilediği görülmüştür. $X u$ (2019), Çin için 2013 yılı verilerini kullanarak demokrasinin mutluluk üzerindeki etkisini test etmiş, demokrasinin mutlulukla pozitif ilişkili olduğunu ortaya koymuştur. Menteş (2020) çalışmasında, dünya ülkeleri için gelir ve demokrasinin mutluluk üzerindeki etkisini analiz etmiştir. Çalışma sonucunda, mutluluğu demokrasinin zayıf, gelirin güçlü etkilediği bulgusunu elde etmiştir.

Araştırmalar neticesinde, mutluluğu etkileyen birçok faktörün olduğu, çalışmanın konusu özelinde, mutluluk ve demokrasi ilişkisini araştıran çalışmaların sınırlı olduğu, yapılan çalışmaların genel olarak sıralı nitel tercih analizlerine dayandığı görülmektedir. Çoğunlukta olan görüş, demokrasi ve mutluluk arasında pozitif bir ilişkinin olduğu yönündedir. Çalışmalarda yoğunlukla demokrasi ve mutluluk arasında pozitif bir ilişkinin olduğu (Frey ve Stutzer, 1999; Frey ve Stutzer, 2000; Frey ve Stutzer, 2002; Frey, 2011; Inglehart, 2008; Inglehart ve Ponarin, 2013; Xu, 2019; Ekici ve Koydemir, 2014; Graham ve Pettinato, 2000; Knutsen, 2015; Dimitrova, 2016; Kroll, 2012; Potts, 2016); az sayıda pozitif bir ilişkinin olmadığı (Dorn, Fischer, Kirchgassner ve Sousa-Poza, 2007; Loubser ve Steenekamp, 2016; Steffen ve Vatter, 2012) tespit edilmiştir. Bunun yanı sıra literatürde çeşitli ülkeler (Shahbaz ve Aamir 2008; Frey ve Stutzer, 1999; Frey ve Stutzer, 2000; Frey ve Stutzer, 2002; Frey, 2011; Inglehart, 2008; Inglehart ve Ponarin, 2013; Steffen ve Vatter, 2012); ülke grupları (Perovic ve Golem, 2010; Abounoori ve Asgarizadeh, 2013; Güzel, 2018; Kabakç1, Günay ve Ata, 2018; Servet, 2018; Aksaraylı ve Kaya, 2020; Graham ve Pettinato, 2000; Dorn vd., 2007; Kroll, 2012; Knutsen, 2015; Dimitrova, 2016; Loubser ve Steenekamp, 2016; Menteş, 2020); Türkiye üzerine yapılan çalışmalar (Servet, 2017, Ekici ve Koydemir, 2014) da mevcuttur. Özetle; literatürde mutluluğu etkileyen birçok faktör ve farklı örneklem grupları ile yöntemler söz konusudur. Ancak belirtilmelidir ki; bu çalışmada demokrasinin mutluluğa etkisi gelir değişkeni kullanılarak belirlenmeye çalışılmıştır.

\section{Veri Seti ve Yöntem}

Çalışmada demokrasinin, kalkınma göstergesi olarak nitelendirilen mutluluk üzerindeki etkisi araştırılmaktadır. Çalışmada oluşturulan iktisadi model aşağıdaki gibidir:

Mutluluk = $\mathrm{f}($ Demokrasi, Kişi Başına GSYH $)$

HAPPINESS = f(DEMOCRACY, GDP $)$

HAPPINESS, mutluluk düzeyini göstermekte olup bağımlı değişkendir; DEMOCRACY ve GDP sırasıyla demokrasi düzeyi ve kişi başına GSYH olup 
bağımsız değişkenlerdir. Çalışmada kişi başına GSYH kontrol değişken olarak kullanılmaktadır. Bağımlı değişkenin sıralı sayı olması sebebiyle analizlerde sıralı nitel tercih modellerin kullanılmasının daha uygun olacağı ifade edilebilir.

Sıralı nitel tercih modelleri, sıralı logit ve sıralı probit modellerini ifade etmektedir. Sıralı logit ve probit modellerde bağımlı değişken kesikli değerler alabilmektedir. Ancak bu, kesikli değer alan bağımlı değişkenin nitel bir değişken olduğu anlamına gelmez. Dolayısıyla çoklu tercih modellerinde değişkenler kategorik ve kategorik olmayan değişkenler şeklinde sınıflandırılabilmektedir. Bu sebeple sıralı değişkenler kategorik değişkenler içerisinde yer almaktadır (Özer, 2004, s. 81-82).

Ekonometrik modellerde parametre tahmininde çeşitli teknikler kullanılmaktadır. Bunlardan en bilinenleri En Küçük Kareler Yöntemi ve En Yüksek Olabilirlik Yöntemidir. Şayet bağımlı değişken kategorik ve sıralı bir değişken ise bu yöntemlerden en yüksek olabilirlik yönteminin kullanılması uygundur (Gujarati ve Porter, 2014, s. 555). Aynı şekilde sıralı logit ve probit modeller için parametre tahminlerinde en küçük kareler yönteminin uygun olmayacağı, bu sebeple en yüksek olabilirlik yönteminin uygulanması gerektiği belirtilmektedir (Karabacak, 2018, s. 77). Çünkü kategorik sıralı verilere EKK uygulanması; sıralı ve kategorik bağımlı değişken değerleri arasında ya da aralığın dışında anlamsız tahminlere sebep olabilir. Buradan hareketle bağımlı değişken sıralı ve kategorik ise tahmin yöntemi olarak sıralı logit / probit modellerin kullanılması daha uygun olacaktır. Bağımlı değişkenin sıralı olduğu durumlarda en küçük kareler yöntemi regresyon varsayımlarının ihlal edilmesi nedeniyle en küçük kareler yönteminin kullanımı uygun değildir. Çünkü eğer en küçük kareler yöntemi varsayımları sağlanamazsa; sıralı bağımlı değişken tahminleri anlamsız olabilir, tutarsız standart hatalara ve $t$ ile F istatistiklerine sebep olabilir. Söz konusu durum yanlış hipotezlerin test edilmesine, uyum iyiliği bakımından $\mathrm{R}^{2}$ değerlerinin yanlış tahmin edilmesine yol açabilir. $\mathrm{Bu}$ nedenlerle sıralı logit ve sıralı probit modellerinin kullanılması önerilmektedir. Hem sıralı logit hem de sıralı probit model tahmini için en yüksek olabilirlik yöntemi kullanılmaktadır (Kızılgöl, 2009, s. 55).

$\mathrm{J}+1$ alternatifli bir durumda basit bir sıralı model aşağıdaki şekilde oluşturulabilir:

$P(Y=j)=F\left(\mu_{j+1}-\beta^{\prime} X\right)-F\left(\mu_{j}-\beta^{\prime} X\right)$

$\mathrm{j}=0,1, \ldots ., \mathrm{J} \quad \mu_{0}=-\infty \quad \mu_{\mathrm{j}} \leq \mu_{\mathrm{j}+1} \quad \mu_{\mathrm{j}+1}=\infty$

$\mu$ 'ler bilinmeyen ve tahmin edilebilecek olan katsayılar, $F$ birikimli dağılım fonksiyonu olup, $\Phi$ standart normal dağılımı, $\Lambda$ lojistik dağılım fonksiyonunu göstermek üzere $F=\Phi$ olursa model siralı probit model, $F=\Lambda$ olursa model siralı logit modeli ifade etmektedir. Siralı nitel tercih modellerinden hangisinin tercih edileceği bilgi kriterleri (AIC ve BIC) ve pseudo $\mathrm{R}^{2}$ 'ne göre belirlenmektedir. Siralı nitel tercih modellerinin katsayılarının yorumlanması ise marjinal etkilerin 
hesaplanması yoluyla yapılmaktadır. Marjinal etkiler, bağımlı değişken ile bağımsız değişkenler arasındaki ilişkiyi ölçmekte ve bağımsız değişkenlerdeki değişmelerin bağımlı değişken üzerindeki her bir tercihin olasılığını göstermektedir.

Çalışmada 8 yükselen ülkenin 2013-2018 dönemi verileri kullanılarak demokrasinin mutluluk düzeyine etkisi siralı nitel tercih analizi ile incelenmektedir. Araştırmada kullanılan değişkenler, değişkenlerin açıklaması ve elde edildikleri kaynaklar aşağıda Tablo 1'de sunulmuştur.

Tablo 1: Kullanılan Değişkenler ve Kaynakları

\begin{tabular}{|c|c|c|c|}
\hline Değişken & $\begin{array}{l}\text { Değişken } \\
\text { Türü }\end{array}$ & Açıklama & Kaynak \\
\hline HAPPINESS & $\begin{array}{l}\text { Bağımlı } \\
\text { Değişken }\end{array}$ & $\begin{array}{l}\text { Mutluluk ölçüsü } \\
\text { olup World } \\
\text { Happiness Report } \\
\text { Mutluluk } \\
\text { Endeksine } \\
\text { dayanmaktadır. } \\
\text { Düşük, orta, } \\
\text { yüksek olmak } \\
\text { üzere üç düzeyli } \\
\text { kategori olarak } \\
\text { ölçeklendirilmiştir. }\end{array}$ & $\begin{array}{l}\text { World Happiness Report } \\
\text { https://worldhappiness.report/ }\end{array}$ \\
\hline DEMOCRACY & $\begin{array}{l}\text { Bağımsız } \\
\text { Değişken }\end{array}$ & $\begin{array}{l}\text { Demokrasi ölçüsü } \\
\text { olup Freedom } \\
\text { House Endeksine } \\
\text { dayanmaktadır. } 1 \\
\text { ile } 7 \text { değerleri } \\
\text { arasında olup } 1 \text { en } \\
\text { yüksek demokrasi, } \\
7 \text { en düşük } \\
\text { demokrasi } \\
\text { düzeyini gösterir. }\end{array}$ & $\begin{array}{l}\text { Freedom House } \\
\text { https://freedomhouse.org/ }\end{array}$ \\
\hline GDP & $\begin{array}{l}\text { Bağımsız } \\
\text { Değişken }\end{array}$ & Kişi başına GSYH & $\begin{array}{l}\text { World Bank, } \\
\text { World Development Indicator } \\
\text { (WDI) } \\
\text { https://databank.worldbank.org/data/ }\end{array}$ \\
\hline
\end{tabular}

HAPPINESS ile temsil edilen mutluluk değişkeni, Dünya Mutluluk Raporunun mutluluk endeksine dayanmaktadır. Mutluluk endeksinin en düşük değeri 0 , en yüksek değeri 10'dur. 0'a yaklaştıkça mutluluk azalmakta, 10'a yaklaştıkça mutluluk artmaktadır. Endeks düşük, orta ve yüksek mutluluk düzeyi olmak üzere üç kategoriye ayrılmıştır. Kategorilendirme işlemi literatürden hareketle Akın ve Şentürk (2012) çalışmalarında olduğu gibi farklı şekillerde kategori ayrımı denenerek $\mathrm{R}^{2}$, model uygunluk istatistikleri ve parametre anlamlılıkları göz önüne 
alınarak değerlendirilmiş, en iyi sonuçları veren mutluluk kategorileri belirlenmiştir. Bu sebeple 5'e kadar olan değerler "düşük düzey mutluluk", 5'den 6'ya kadar olan değerler "orta düzey mutluluk" ve 6'dan sonraki değerler "yüksek düzey mutluluk" olarak ifade edilmiştir. Mutluluk düzeyi düşük düzey mutluluktan yüksek düzey mutluluğa (1'den 3'e) doğru üç düzeyde gösterilmiştir. 1. düzey düşük düzey mutluluk, 2. düzey orta düzey mutluluk ve 3 . düzey yüksek düzey mutluluktur.

Çalışmada ekonometrik yöntem olarak sıralı nitel tercih modelleri kullanılmaktadır. Çünkü bağımlı değişken olarak kullanılan mutluluk endeksi 0 ile 10 arasında değerler alan sıralı bir değişken olduğu için, sıradan en küçük kareler tahmin yöntemini kullanarak regresyon modelini tahmin etmek yerine siralı nitel tercih modellerini kullanmak daha uygun olacaktır. Çalışmada mutluluk değişkeninin sıralı ve kategorik bir nitelik taşıması dolayısıyla değişkeni açıklamada daha uygun olan sıralı logit ve probit model tahmini yapılmaktadır.

\section{Bulgular}

Analizlere başlamadan önce önsel bilgi edinebilmek amacıyla çalışmada kullanılacak değişkenlere ait tanımlayıcı istatistiklere yer verilmiştir. BRIC ve MIST ülkeleri için tanımlayıcı istatistikler Tablo 2'de sunulmuştur.

Tablo 2: Değişkenlere Ait Tanımlayıcı İstatistikler

\begin{tabular}{lccccc}
\hline \multicolumn{1}{c}{ Değişken } & Gözlem & Ortalama & $\begin{array}{c}\text { Standart } \\
\text { sapma }\end{array}$ & Minimum & Maksimum \\
\hline HAPPINESS & 48 & 2.125 & 0.640 & 1 & 3 \\
DEMOCRACY & 48 & 3.458 & 1.989 & 1 & 7 \\
GDP & 48 & 19419.29 & 10299.74 & 4809.648 & 41894.11 \\
\hline
\end{tabular}

Çalışmada mutluluk endeksi değişkeni düşük, orta ve yüksek düzey mutluluk olmak üzere üç kategoriye ayrıldığından mutluluk değişkeninin en düşük değeri 1 iken, en yüksek değeri 3'tür. Ortalama mutluluğa bakıldığında, BRIC ve MIST ülkelerinde mutluluk düzeyinin yüksek düzeye yakın olduğu görülmektedir. Demokrasi endeksi değişkeninin en yüksek değeri (demokrasi düzeyi en düşük değeri) 7, demokrasi endeksinin en düşük değeri (demokrasi düzeyi en yüksek değeri) 1 ve ortalama demokrasi 3.458 'dir. Söz konusu ülkelerin demokratikleşme yolunda olduğu anlaşılmaktadır. Diğer taraftan kişi başına GSYH'nin en düşük değeri 4809.648, en yüksek değeri 41894.11, ortalama değeri 10299.74'dir.

Siralı nitel tercih modelleri olan siralı logit ve siralı probit modellerinden hangisinin analizde kullanılacağına karar vermek için her iki model de tahmin edilmiştir. Tablo 3'de sıralı nitel tercih modellerinden sıralı logit ve probit mutluluk modellerinin karşılaştırılması sonuçları görülmektedir. 
Tablo 3: Sıralı Logit ve Probit Mutluluk Modellerinin Karşılaştırııması

\begin{tabular}{lll}
\hline Model & $\begin{array}{l}\text { Suralı Logit } \\
\text { Model }\end{array}$ & $\begin{array}{l}\text { Suralı Probit } \\
\text { Model }\end{array}$ \\
\hline DEMOCRACY & -0.253 & $-0.159^{*}$ \\
LNGDP & $1.936^{* * *}$ & $1.180^{* * *}$ \\
\hline McFadden R ${ }^{2}$ & 0.141 & 0.156 \\
AIC (Akaike bilgi kriteri) & 86.266 & 84.887 \\
BIC (Bayes bilgi kriteri) & 93.751 & 92.371 \\
Log likelihood & -39.133 & -38.443 \\
LR istatistik & 12.83 & 14.21 \\
Prob.(LR) & 0.000 & 0.000 \\
Gözlem Sayıs1 & 48 & 48 \\
\hline Not: ***, ** ve * işaretleri, \%1, \%5 ve \%10 düzeylerinde istatistiksel anlamlılı̆̆ \\
göstermektedir.
\end{tabular}

Sıralı logit ve probit modeller birbirlerine çok benzer olmakla birlikte literatürde modellerden hangisinin tercih edileceğine dair çeşitli kriterler mevcuttur. Yapılan

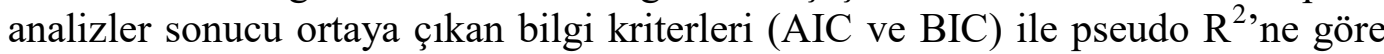
karar verilebilmektedir. Şayet sıralı probit modeldeki bilgi kriterleri sıralı logit modeldeki bilgi kriterlerinden düşük ve sıralı probit modeldeki pseudo $\mathrm{R}^{2}$ değeri sıralı logit modeldeki pseudo $\mathrm{R}^{2}$ değerinden büyükse sıralı probit model tercih edilmektedir. Tablo 3'de siralı probit modelde bilgi kriterleri siralı logit modele göre düşük olup, pseudo $\mathrm{R}^{2}$ değerleri bakımından daha büyüktür. $\mathrm{O}$ halde bu kriterlere göre sıralı probit modelin seçilmesi uygun olacaktır.

Tablo 4: Suralı Probit Model Tahmin Sonuçları

\begin{tabular}{lllrrrr}
\hline $\begin{array}{l}\text { Bağımsız } \\
\text { Değişkenler }\end{array}$ & Katsayılar & $\begin{array}{l}\text { Standart } \\
\text { Hata }\end{array}$ & z-değeri & \multicolumn{3}{c}{ Marjinal Etkiler } \\
\hline & & & & $\begin{array}{l}\text { Yüksek } \\
\text { düzey }\end{array}$ & $\begin{array}{l}\text { Orta } \\
\text { düzey }\end{array}$ & \multicolumn{1}{c}{$\begin{array}{l}\text { Düş̈̈k } \\
\text { düzey }\end{array}$} \\
\hline DEMOCRACY & $0.159^{*}$ & 0.092 & -1.72 & -0.046 & 0.021 & 0.026 \\
LNGDP & $1.180^{* * *}$ & 0.348 & 3.38 & 0.345 & -0.154 & -0.191 \\
\hline Gözlem Sayıs1 & 48 & & & & & \\
Prob>Ki-Kare & 0.0000 & & & & & \\
Pseudo R ${ }^{2}$ & 0.1560 & & & & & \\
\hline$\mu_{1}$ & 9.577 & 3.219 & & & & \\
$\mu_{2}$ & 11.705 & 3.394 & & & & \\
\hline
\end{tabular}

Not: $\mu$ 'ler kesim noktalarını (uç değerleri) göstermektedir. ***, ** ve * işaretleri, \%1, \%5 ve \%10 düzeylerinde istatistiksel anlamlılı̆̆ı göstermektedir.

Tablo 4'de birinci sütunda bağımsız değişkenler, ikinci sütunda sıralı probit model sonucu elde edilen katsayılar, üçüncü sütunda katsayılara ait standart hatalar, dördüncü sütunda katsayıların $\mathrm{z}$ değerleri ve beşinci sütunda bağımsız değişkenlerin bağımlı değişken üzerindeki marjinal etkileri görülmektedir. Probit modeller doğrusal bir model olmadıklarından probit model tahmin sonucu elde edilen katsayılar doğrudan yorumlanamamakta ancak, katsayıların işaretleri üzerinde durulabilmektedir. $\mathrm{Bu}$ nedenle probit modellerde katsayıları 
yorumlayabilmek için marjinal etkiler hesaplanmaktadır. Marjinal etkiler hesaplandıktan sonra her bir katsayı yorumlanabilmekte, $\mathrm{z}$ değerlerinin olasılık değerlerine göre de katsayıların istatistiki bakımdan anlamlılıklarına bakılabilmektedir. Yani modelde her bir bağımsız değişkenin mutluluk düzeyi üzerindeki sayısal etkisi incelenmektedir. Marjinal etki, bağımsız değişken bir birim arttığında mutluluk düzeyi kategorisindeki değişme olasılığını göstermektedir.

Tahmin edilen panel sıralı nitel tercih modeli (sıralı probit model) sonuçlarına göre; demokrasi değişkeni \%10, kişi başına GSYH değişkeni \%1 düzeyinde istatistiksel olarak anlamlıdır. Diğer taraftan değişkenlere ait katsayı işaretleri beklentisi demokrasi değişkeni için negatif, kişi başına GSYH değişkeni için pozitiftir. Çünkü demokrasi değişkeni 1 ve 7 değerleri arasında 1 en yüksek değeri, 7 en düşük değeri gösterdiğinden işaretin negatif olması beklenmektedir. Yani 1'e yaklaştıkça demokrasi endeksi düşmekte ancak demokrasi düzeyi yükselmekte; 7'ye yaklaştıkça demokrasi endeksi yükselmekte ancak demokrasi düzeyi düşmektedir. Diğer bir ifadeyle, demokrasi endeks değerinin artması demokrasi düzeyinin azalması; demokrasi endeks değerinin azalması demokrasi düzeyinin artması anlamına gelmektedir. Bu sebeple demokrasi endeksi düşerse (demokrasi düzeyi artarsa) ve kişi başına GSYH artarsa mutluluk endeksi (mutluluk düzeyi) artar. Çalışmada demokrasi değişkeni mutluluk düzeyi ile negatif ilişkili, kişi başına GSYH mutluluk düzeyi ile pozitif ilişkilidir ve değişkenlerin katsayı işaretleri beklenildiği gibi çıkmıştır.

Katsayıları yorumlayabilmek için tahminde marjinal etkiler bağımlı değişkenin sadece en yüksek mutluluk kategorisi üzerindeki marjinal etkilerini göstermektedir. Hesaplanan marjinal etki sonuçlarına göre; demokrasi değişkenine ait marjinal etki, bu değişkenin mutluluk düzeyine ilişkin en yüksek kategorinin olasılığını 0.046 birim azaltmaktadır. Yani demokrasi endeksi düştükçe demokrasi artmakta bu da mutluluk düzeyini artırmaktadır. Kişi başına GSYH değişkenine ait marjinal etki, bu değişkenin mutluluk düzeyine ilişkin en yüksek kategorinin olasılığını 0.345 birim arttırmaktadır. Demokrasi endeksi düştükçe ve kişi başına GSYH arttıkça mutluluk endeksi ve mutluluk düzeyi artmaktadır. Ayrıca tahmin edilen sıralı probit modelde ki-kare test istatistiğine göre model bir bütün olarak anlamlıdır. Siralı probit modelde modelin uygun olup olmadı̆̆ı uyum iyiliği "Sözde $R^{2}$ Değeri (Pseudo $R^{2}$ )" testi ile yapılmaktadır. Buna göre bağımlı değişkendeki toplam değişimin \%15'i bağımsız değişkenler tarafından açıklanabilmektedir. Diğer taraftan yüksek, orta ve düşük mutluluk düzeyleri karşılaştırılarak, orta ve düşük mutluluk düzeyine ilişkin marjinal etkiler değerlendirildiğinde değişkenlerin hem olasılık değerlerinin hem de katsay1 işaretlerinin beklenildiği gibi çıkmadığ 1 görülmüştür. Demokrasinin mutluluğun daha yüksek düzeylerinde daha etkili olduğu, orta ve düşük düzeylerinde etkili olmadığı anlaşılmıştır. 


\section{Sonuç}

Çalışmada demokrasinin mutluluk düzeyi üzerindeki etkisi, BRIC ve MIST ülkelerini kapsayacak şekilde 8 yükselen ülkenin 2013-2018 dönemi verileri kullanılarak ampirik olarak araştııılmıştır. Demokrasi göstergesi olarak Freedom House Demokrasi Endeksi, mutluluk göstergesi olarak Dünya Mutluluk Endeksi kullanılmıştır. Bağımlı değişken olarak kullanılan Dünya Mutluluk Raporunun Mutluluk Endeksi, sıralı ve kategorik bir nitelik taşıdığından, demokrasinin mutluluk düzeyi üzerindeki etkisini belirlemek için panel sıralı nitel tercih analiz yöntemi kullanılmıştır.

Analiz sonuçlarına göre, demokrasi ve kişi başına GSYH istatistiksel olarak anlamlıdır ve değișkenlerin katsayı işaretleri beklenilen yöndedir. Buna göre demokrasi endeksi mutluluk düzeyine ilişkin en yüksek kategorinin olasılığını azaltırken, kişi başına GSYH mutluluk düzeyine ilişkin en yüksek kategorinin olasılığını artırmaktadır. Bir diğer deyişle, demokrasi endeksindeki azalış (demokrasi düzeyindeki artış) ve kişi başına GSYH'deki artış mutluluğu artırmaktadır. Tahmin sonuçlarına göre, mutluluğun daha yüksek seviyelerinde demokrasinin mutluluk üzerinde daha etkili olduğu söylenebilir. Çünkü mutluluğun düşük ve orta düzeylerinde demokrasinin mutluluğu etkileme olasılığı düşük iken, yüksek mutluluk düzeyini etkileme olasılığı yüksektir. Mutluluğun düşük ve orta düzeylerinde demokrasinin mutluluk üzerindeki etkisi yüksek mutluluk düzeyine göre daha düşüktür.

Çalışma demokrasinin artması durumunda mutluluk düzeyinin artacağını göstermektedir. Demokrasi mutluluğu artıran bir faktördür ve 8 yükselen ekonomi ülkesinde demokrasi düzeyinde meydana gelecek artışların mutluluğu artıracağı anlaşılmaktadır. Çalışmada demokrasinin mutluluğu artırdığı sonucu elde edilse de, BRIC ve MIST ülkelerinde mutluluk düzeyinin daha yüksek düzeye çıkarılabilmesi için birkaç politika önerisinde bulunulabilir. BRIC ve MIST ülkelerinde gelir artışının yanı sıra politik alanda iyileşmenin gerçekleştirilmesi gerekir. Politik alanda demokratik koşulların iyi bir şekilde oluşturulması mutluluk üzerinde olumlu yönde etkili olacaktır. Yani söz konusu ülkelerde yüksek sürdürülebilir büyümeye yüksek demokrasi düzeyinin eşlik etmesi gerekir. Çünkü demokrasinin olmadığı toplumlarda belirsizlik hakim olmakta, bu durum ülke refahı özelinde ülkelerin mutsuzluğuna yol açabilmektedir. Diğer taraftan yükselen ülkelerde ekonomik ve siyasi istikrar ile altyapı ve hukuki hizmetlerin tam olarak sağlanması, ekonomi ve siyasette hızlı değişimlerin önüne geçilmesi, ekonomik ve politik belirsizliğin azaltılması, demokratik işleyişin gerçekleşmesine engel olan politikacı ve yöneticilerin önlenmesi gerekmektedir ki bu şekilde söz konusu ülkelerde mutluluğun artışı sağlanabilir. 


\section{Kaynakça}

Abounoori, E. ve Asgarizadeh, D. (2013). Macroeconomic factors affecting happiness. International Journal of Business and Development Studies, 5(1), 5-22.

Akın, H. B. ve Şentürk, E. (2012). Bireylerin mutluluk düzeylerinin ordinal lojistik regresyon analizi ile incelenmesi. Öneri Dergisi, 10(37), 183-193.

Aksaraylı, M. ve Kaya, H. (2020). Ekonomik özgürlük ve mutluluk endeksleri temelinde ülkeler için kümeleme analizi. https://d1wqtxts1 xzle7.cloudfront.net/64409348/Tam-Metinler.pdf/(Erişim Tarihi: 14 Temmuz 2020)

Aktaş, M. T. (2015). Mutluluğun durağan durum hali: yoksulluk açısından uyum teorisine dayalı bir analiz. HAK-IŞ Uluslararası Emek ve Toplum Dergisi, $4(10), 44-65$.

Dimitrova, L. (2016). Democracy, economy and happiness in post-soviet states (1995-2014). Yayınlanmamış Yüksek Lisans Tezi, University of Tartu Faculty of Social Sciences Johan Skytte Institute of Political Studies, Tartu.

Dorn, D., Fischer, J.A.V, Kirchgassner, G., ve Sousa-Poza, A. (2007). Is it culture or democracy? the impact of democracy and culture on happiness. Social Indicators Research, 82, 505-526.

Easterlin, R. (1974). Does economic growth improve the human lot? Some empirical evidence. P. David ve M. Reder (Ed.), Nations and Households in Economic Growth içinde (s. 89-125). New York: Academic Press.

Ekici, T. ve Koydemir, S. (2014). Social capital, government and democracy satisfaction, and happiness in Turkey: a comparison of surveys in 1999 and 2008. Soc Indic Res., 118, 1031-1053.

Frey, B. S. (2011). Tullock challenges: happiness, revolutions, and democracy. Public Choice, 148, 269-281.

Frey, B. S. ve Stutzer, A. (1999). Happiness prospers in democracy. Journal of Happiness Studies, 1, 79-102.

Frey, B. S. ve Stutzer, A. (2000). Happiness, economy and institutions. The Economic Journal, 110, 918-938.

Frey, B. S. ve Stutzer, A. (2002). What can economists learn from happiness research?. Journal of Economic Literature, 40, 402-435. 
Graham, C. ve Pettinato, S. (2000). Happiness, markets, and democracy: Latin America in comparative perspective. Journal of Happiness Studies, 2, 237-268.

Güzel, S. (2018). Gelir eşitsizliği, refah ve mutluluk. Anemon Muş Alparslan Üniversitesi Sosyal Bilimler Dergisi, 6(3), 389-394.

Gujarati, D. M. ve Porter, D. C. (2014). Temel ekonometri. (Ü. Şenesen ve G. Günlük Şenesen, Çev.). İstanbul: Literatür Yayıncılık.

Helliwell, J., Layard, R. ve Sachs, J. (2017). World happiness report. https://worldhappiness.report/ (Erişim Tarihi: 25 Temmuz 2019)

Inglehart, R. (2008). Development, freedom, and rising happiness: A global perspective (1981-2007). Perspectives on psychological science, 3(4), 264-285.

Inglehart, R. F. ve Ponarin, E. D. (2013). Happiness and democracy, 1972-2008. Journal of Siberian Federal University Humanities \& Social Sciences, 8(6), 1097-1106.

Kabakçı Günay, E. ve Ata, O. (2018). Gelir mutluluk getirir mi? Ülkelerin gelir ve mutluluk düzeyleri arasındaki ilişkiye yönelik bir değerlendirme. Kesit Akademi Dergisi, 4(17), 161-192.

Karabacak, E. (2018). Türkiye'de ulaştırma hizmetlerinden duyulan memnuniyetin genelleştirilmiş sıralı logit modelleri ile analizi. Yayımlanmamış Yüksek Lisans Tezi. Atatürk Üniversitesi Sosyal Bilimler Enstitüsü, Erzurum.

Kızılgöl, Ö. (2009). Türkiye'de yoksulluk sorunu: ekonometrik bir baklş. Yayımlanmamış Doktora Tezi. Dokuz Eylül Üniversitesi Sosyal Bilimler Enstitüsü, İzmir.

Knutsen, C. H. (2015). GDP, Inequality, democracy and the happiness of nations. https://www.sv.uio.no/esop/english/publications/unpublishedworks/working-papers/2010/knutsen-2010-gdp.html (Erişim Tarihi: 14 Temmuz 2020)

Kroll, C. (2012). The greatest happiness principle: an imperative for social democracy?. H. Meyer ve J. Rutherford (Ed.), The future of european social democracy building the good society içinde (s. 120-134). London: Palgrave Macmillan.

Loubser, R. ve Steenekamp, C. (2016). Democracy, well-being, and happiness: A 10-nation study. Journal of Public Affairs, 17, 1-12. 
Menteş, N. (2020). Mutluluk, gelir ve demokrasi: Dünya ülkeleri için yapısal eşitlik modeli önerisi. İnsan ve Toplum Bilimleri Araştırmaları Dergisi, 9 (3), 2138-2153.

Özer, H. (2004). Nitel değişkenli ekonometrik modeller teori ve bir uygulama. Ankara: Nobel Basımevi.

Perovic, L.M. ve Golem, S. (2010). Investigating macroeconomic determinants of happiness in transition countries. Eastern European Economics, 48(4), 5975 .

Potts, J. (2016). Democracy and happiness: a true correlation?. Journal of Arts \& Humanities, 5(3), 86-92.

Servet, O. (2017). Mutluluğun Türkiye'deki belirleyenlerinin zaman içinde değişimi. Akdeniz I.I. B.F. Dergisi, 35, 16-42.

Servet, O. (2018). Dünya ülkelerinde mutluluğu belirleyen faktörler üzerine bir uygulama: siral logit model. Journal of Emerging Economies and Policy, $3(2), 1-22$.

Shahbaz, M. ve Aamir, N. (2008). Macroeconomic determinants of the happiness of the poor: a case study of Pakistan. Towards Global Transformation: Proceedings of the Third International Conference on Gross National Happiness (367-389). Thimphu: The Centre for Bhutan Studies.

Steffen, I. S. ve Vatter, A. (2012). Does satisfaction with democracy really Increase happiness? Direct democracy and individual satisfaction in Switzerland. Polit Behav, 34, 535-559.

Veenhoven, R. (2006). How do we assess how happy we are? Tenets, implications and tenability of three theories. https://www.researchgate.net/publication/228364106_3_How_do_we_asse ss_how_happy_we_are_Tenets_implications_and_tenability_of_three_the ories. (Erişim Tarihi: 16 Mayıs 2021)

Xu, L. (2019). The more, the merrier? on the relationships of democracy and happiness in China. Advances in Social Science, Education and Humanities Research, 402, 133-137. 


\section{Democracy and Happiness: A Research on BRIC and MIST Countries}

\section{Extended Abstract}

\section{Introduction}

In order for individuals to lead a better life, their individual abilities and freedoms need to be expanded as well as improving their financial conditions. Thus, a concept such as happiness came to the fore besides the increase in per capita income in increasing welfare. This situation has brought the development from a different perspective on the agenda. Happiness; it can be evaluated from a broad perspective including development in terms of housing, health, education, per capita income, welfare level, income distribution, freedoms, good management, working status, leisure time, family and social relations, and environmental values. Recently, development has an important relationship with happiness since it has a human-centered understanding. Happiness is among the most important indicators of development, and happy societies have a higher potential to stand out in the development race. People will be happier depending on the improvement in their living standards brought about by the increase in their per capita income. Increasing happiness is necessary for economic development. On the other hand, democracy is a political factor that plays an important role in increasing happiness in the development of countries. The relationship of democracy to happiness is a model for shaping the influence of the political regime. There are two ways in which the political regime can affect happiness: the relationship between ideology and political regime and institution building and dependence on the political regime. Therefore, it is possible to assume that the level of happiness should vary between political regimes. There is expected that countries that rank high in terms of democracy level are the happiest countries. The relationship between democracy and happiness has not been sufficiently investigated in the happiness literature. In this context, the study aims to analyze the effect of democracy on the level of happiness in 8 countries consisting of existing emerging economies (BRIC) and newly emerging economies (MIST).

\section{Method}

In the study, ordered qualitative choice models (ordered probit model) were used as econometric method. Because the happiness index used as the dependent variable is an ordered variable that takes values between 0 and 10, it will not be appropriate to estimate the regression model using the ordinary least squares estimation method. The use of ordered dependent variable OLS violates the OLS regression assumptions. Therefore, it was appropriated to make estimation with ordered qualitative choice models. In the study, it is investigated the effect of democracy on the level of happiness. The happiness index is the dependent variable, its lowest value 0 and the highest value is 10. The happiness index is divided into three categories as low, medium and high happiness levels. The index is shown in three levels from low level happiness to high level happiness (from 1 to 3). Level 1 is low level happiness, level 2 is medium level happiness, and level 3 is high level happiness. HAPPINESS refers to level of happiness and is the dependent variable. DEMOCRACY refers to level of democracy, GDP refers to per capita GDP, which are all independent variables. GDP is used as the control variable. Happiness index is taken from World Happiness Report, democracy index is taken from Freedom House, per capita GDP is taken from World Bank database.

\section{Results and Discussion}

According to the results of the panel ordered qualitative choice model (ordered probit model), democracy variable is statistically significant at $10 \%$ level and per capita GDP variable is 
statistically significant at $1 \%$ level. Democracy is negatively related to the level of happiness, per capita GDP is positively related to the level of happiness and and the coefficient signs of the variables came out as expected. The marginal effect of the democracy variable reduces the probability of the highest category regarding the level of happiness of this variable by 0.046 units. In other words, as the democracy index decreases, democracy increases and this increases the level of happiness. The marginal effect of the per capita GDP variable increases the probability of the highest category regarding the level of happiness of this variable by 0.345 units. The democracy index decreases the probability of the highest category related to the level of happiness. The per capita GDP increases the probability of the highest category related to the level of happiness. As the democracy index decreases and per capita GDP increases, the happiness index and happiness level increase. In addition, the model is significant as a whole according to chi-square test statistics in the ordered probit model. According to the Pseudo R2 test, $15 \%$ of the total change in the dependent variable can be explained by the independent variables.

\section{Conclusion}

According to the ordered probit model estimation results, it can be said that democracy at higher levels of happiness is more effective on happiness. While the probability of democracy affecting happiness at low and medium levels of happiness is low, it is highly likely affect the high level of happiness. The effect of democracy on happiness at the low and medium levels of happiness is lower than the level of high happiness. It has been concluded that democracy increases happiness in the BRIC and MIST countries, and several policy recommendations can be made. The improvement in the political field should be realized besides the income increase in the BRIC and MIST countries. It is necessary to provide full economic and political stability, infrastructure and legal services, to prevent rapid changes in economy and politics, to reduce economic and political uncertainty, and to prevent politicians and administrators who hinder the realization of democratic functioning. In this way, happiness can be increased in these countries. 